This item was submitted to Loughborough's Research Repository by the author.

Items in Figshare are protected by copyright, with all rights reserved, unless otherwise indicated.

\title{
A conceptual approach to support through-life business transformation in an aerospace and defence context
}

PLEASE CITE THE PUBLISHED VERSION

http://dx.doi.org/10.1109/SYSOSE.2010.5544058

PUBLISHER

(C) IEEE

VERSION

VoR (Version of Record)

LICENCE

CC BY-NC-ND 4.0

\section{REPOSITORY RECORD}

Dogan, Huseyin, and Michael Henshaw. 2019. "A Conceptual Approach to Support Through-life Business Transformation in an Aerospace and Defence Context”. figshare. https://hdl.handle.net/2134/7224. 
This item was submitted to Loughborough's Institutional Repository (https://dspace.lboro.ac.uk/) by the author and is made available under the following Creative Commons Licence conditions.

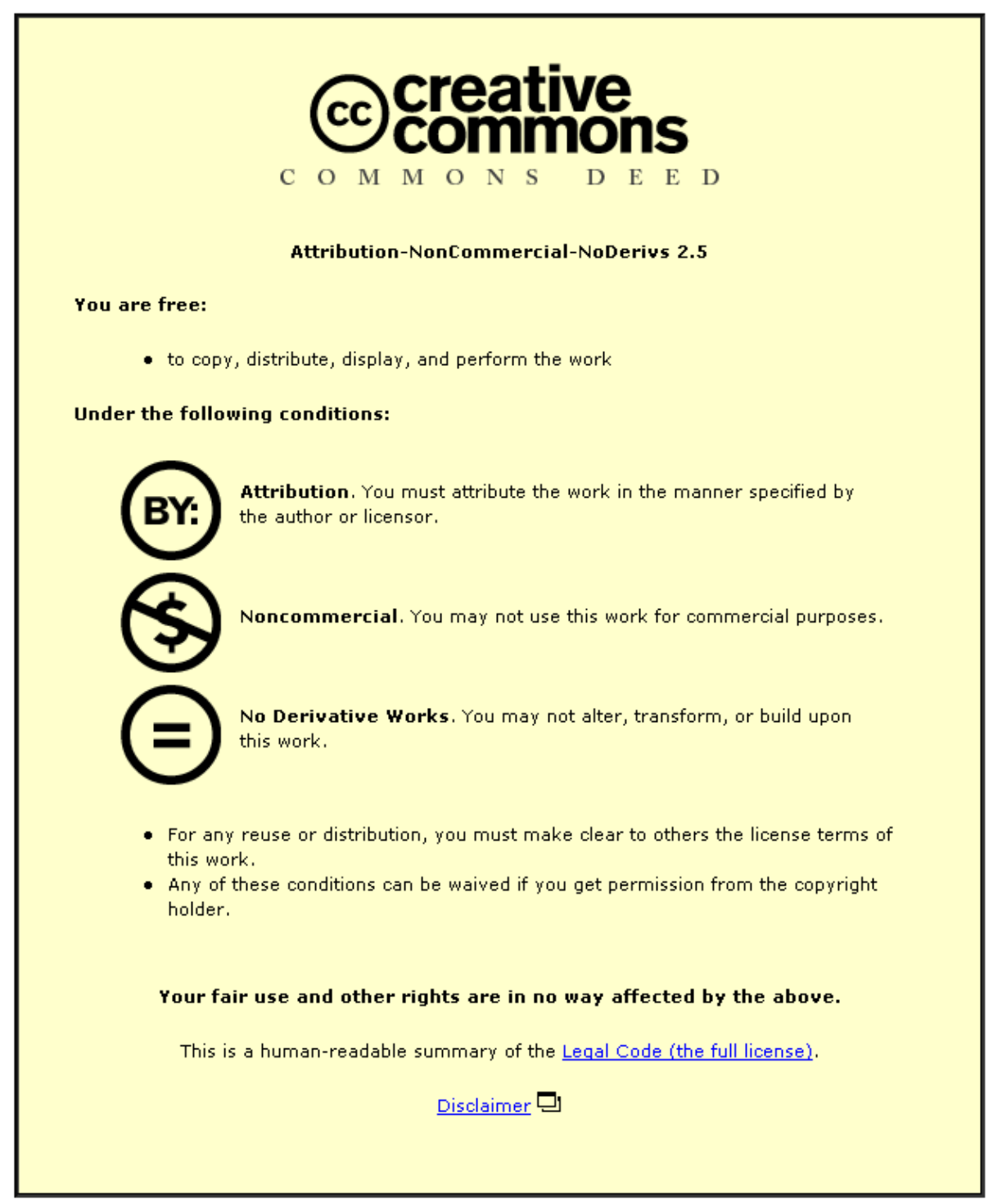

For the full text of this licence, please go to: http://creativecommons.org/licenses/by-nc-nd/2.5/ 


\title{
A conceptual approach to support through-life business transformation in an aerospace and defence context
}

\author{
Huseyin Dogan and Michael Henshaw \\ Loughborough University, Systems Engineering, Garendon Wing, Holywell Park, \\ Leicestershire, LE11 3TU, United Kingdom \\ H.Dogan@,lboro.ac.uk and M.J.d.Henshaw@,lboro.ac.uk
}

\begin{abstract}
Through Life Capability Management (TLCM) is a complex evolving domain that requires a new approach to better understand the different viewpoints, models and practices within various enterprises to support a future conceptual model development. This research applied Soft Systems Methodology (SSM) to identify the activities necessary to transform an existing aerospace and defence business model to one that would support TLCM. Semi-structured interviews were conducted with experts and stakeholders across a range of different relevant functions and organisations to identify the activities required to support conceptual model development. A bottom-up approach was used to provide a TLCM ontology and a top-down approach was proposed to develop the root definitions derived from the experts' perception of TLCM. The benefits and drawbacks of using SSM including the human-activity system and mapping the activities onto a TLCM cube (architectural) model are discussed.
\end{abstract}

Index Terms - TLCM, Capability, Soft Systems, Human Activity Model, Ontology.

\section{INTRODUCTION}

Defence acquisition is trying to evolve into a through-life business by shifting away from the traditional pattern of designing and manufacturing successive generations of platforms, towards a new paradigm centred on support, sustainability and the incremental enhancements of existing capabilities from technology insertions [1]. It is important that all functions and organisations within the supply chain enterprise share a common understanding and language centred on MoD's Through Life Capability Management (TLCM) initiative to support a future conceptual model development.

"TLCM is a multi-year transformation journey often viewed as 5-10 years of change"

[R. Smith, Engineering Director - Typhoon, BAE Systems]

This paper describes a conceptual approach adopted from Soft Systems Methodology (SSM) to develop an ontology to support this TLCM transformation. The results derived from semi-structured interviews conducted with the Subject Matter Experts (SMEs) from the TLCM enterprise indicate substantial differences in SMEs' activity models, perception of TLCM, and the transformation process.

The structure of this paper is as follows:

- Literature analysis: TLCM, the Cube Model and Soft Systems Methodology.

- Case Study: method and results including the human activity models, root definitions, and ontology development to support TLCM.

- Discussion: the SSM process and mapping of activities onto the Cube Model.

- Conclusions.

\section{Through LifE CAPABILITY MANAGEMENT}

TLCM "translates the Defence policy into an approved programme that delivers the required capabilities, through life, across all Defence Lines of Development" (DLoDs ${ }^{l}$ ) where capability in this context is defined as "the continuing ability to generate a desired operational outcome or effect which is relative to the threat, physical environment and the contributions of coalition partners" [2]. There are many different viewpoints to TLCM with some complementing the above definition from the UK MOD Defence Acquisition Operating Framework (AOF) and others considering a more engineering process and equipment centric view. Interview results presented in the later sections indicate that these diverse viewpoints from different communities (e.g. industry, academia and MoD) imply characteristics of both Capability and TLCM.

Our purpose has been to identify the activities needed to support TLCM. These activities are likely to correlate to capability $\left(a_{1}, a_{2}, a_{3}\right.$, etc, $b_{1}, b_{2}, b_{3}$, etc) but only some might be relevant to TLCM $\left(b_{1}, b_{2}, b_{3}\right.$, etc). Those relevant may need to be transformed through a new set of activities $\left(t_{1}, t_{2}, t_{3}\right.$, etc) that are only needed to support TLCM. This can be visualised as interlocking Lego bricks as shown in Figure 1 and will be discussed later.

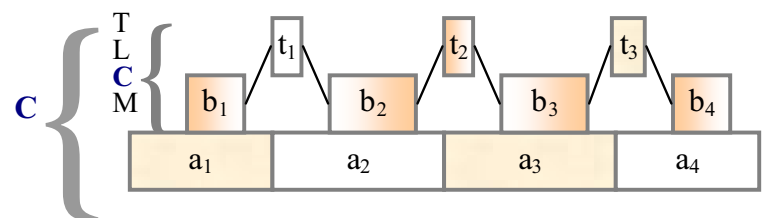

Figure 1. Activities as Lego bricks correlated to TLCM

\footnotetext{
${ }^{1}$ Training, Equipment, Personnel, Information, Doctrine \&

Concepts, Organisation, Infrastructure and Logistics.
} 
Industry development resulted in a model called 'the TLCM cube' [3], which is subdivided into cells specified by level, corresponding to hierarchy of force elements, Lines of Development (LoD), and life-cycle stages as shown in Figure 2.

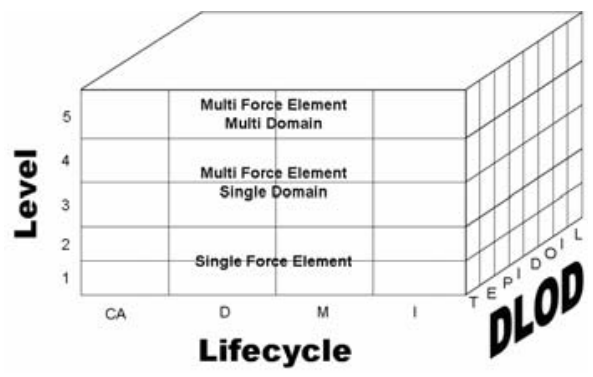

Figure 2. The TLCM cube model in outline

The lifecycle stages of the TLCM cube cover the timeline from concept to retirement. The levels within this threedimensional model are described as Systems Engineering, Systems of Systems Engineering and Capability Management. These levels denote the single- and multi- level force elements including army formations, aircrafts and ships in addition to domains of land, sea and air. For example, a Typhoon aircraft can represent a single-force element but when integrated with a Nimrod maritime surveillance aircraft it becomes a multi-force element with a single domain and if integrated with an aircraft carrier e.g. CVF, it grows to be a multi-force element with a multi-domain interaction.

Industry has also developed a support environment known as TRAiDE ${ }^{\mathrm{TM}}$ (TLCM Robust Acquisition inclusive Decision Environment) which essentially provides an Information Management (IM) environment and capability-relevant toolset to support decision making across the whole acquisition community [4]. Here, TLCM is considered as an IM problem, rather than one of simply equipment, performance and technology management over time [5]. This IM approach was developed into a 'Capability Dashboard' that enables a wide range of stakeholder perspectives to be presented coherently in a single output visualisation [6]. This can be regarded as a plan on a page for decision support and management.

Academic developments in TLCM have included definition of Capability Readiness mapped onto the system development lifecycle [7] and recommendations for Systems Engineering approaches as applied to 'Capability Engineering' and compared with traditional systems engineering [8].

\section{Soft Systems Methodology}

Checkland's SSM can be used to analyse a problem situation for an organisation seeking a better way of working. This approach is appropriate to socio-technical systems, and is particularly relevant when the means of improvement is a new information system and the analysis task is to understand the requirements for this system [9] [10].

The research reported herein adopted a 'soft' systems initiative by using steps three, four and five of Checkland's SSM. That is selecting how to view the situation and producing the root definitions; building conceptual models of what the system must do; and comparison of the conceptual models with the real world. Root definitions are written as sentences that elaborate a transformation. There are six elements that make up a well formulated root definition, which are summed up in the mnemonic CATWOE (Customers, Actors, Transformation process, Worldview, Owners, and Environmental Constraints).

The soft systems approach applied here is not the formal SSM of Checkland, but draws some techniques from it. The difficulty in the TLCM context is getting a common view across the enterprise. TLCM can be viewed as a complex evolving socio-technical system, which makes 'soft' systems an appropriate approach. 'Soft' systems thinking is more appropriate in fuzzy, ill-defined situations involving human beings and cultural considerations, whereas 'hard' systems approaches are appropriate in well-defined technical problems, and hence involve logical rules to engineer solutions [11] Traditional System Engineering and modelling techniques including functional modelling, which has many types such as IDEF0, Data Flow Diagrams, Flow Charts, UML and SysML [12] cannot be constructed without ambiguity due to its complexity and context dependent parameterisation.

The starting point for this analysis is a case study approach which is discussed in the next section.

\section{CASE STUdy: SSM FOR TLCM}

The aim of this case study was to develop a TLCM ontology. SSM is used to identify the activities necessary to support TLCM, including identification of a list of root definitions for TLCM and a human activity model.

\section{A. Method}

A semi-structured interview questionnaire was developed to understand how the SMEs describe 'Capability' and 'TLCM' as industry's perception and MoD's viewpoint of these terms may differ. The interview questionnaire subsequently adopted SSM's root definitions, CATWOE mnemonics and conceptual model development techniques to derive a set of activities needed to transform an aerospace and defence business model into one to support TLCM. A bottom-up approach was used by the Authors to provide a level of abstraction in developing a TLCM ontology and a top-down approach is proposed to develop the root definitions.

\section{B. Results}

This section summarises and discusses the transcribed semistructured interview results. 


\section{1) Stakeholder Characteristics}

The stakeholders were chosen from three different types of organisations within the supply chain; industry (number of interviewees, $n=9)$, academia $(n=2)$ and Ministry of Defence $(\mathrm{n}=5)$, where $\mathrm{MoD}$ is the customer. The industrial stakeholders were chosen from a single prime aerospace and defence company that consisted of the air, land and maritime domains of the through-life business. All stakeholders were either researching or managing TLCM. A broad group of stakeholders was chosen from the different functions including project management; supply chain management; maintenance and service support; technical; and human resources to give sufficient coverage of activity types and to identify the necessary activities to support TLCM and its ontology development. The stakeholders $(\mathrm{n}=16)$ spend, on average, $87 \%$ of their time supporting TLCM.

\section{2) Capability and TLCM Contextualisation}

The stakeholders were asked to describe Capability and TLCM in addition to their perception of MoD's and industry's view of both. The UK MoD AOF [2] definition of Capability which is described as the continuing ability to generate a desired operational outcome and effect is re-instantiated by most participants. The result showed that the term 'capability' can be applied to business (industrial), military (operational), technical and individual capability. Stakeholders' perception of MoD's view of capability centred on integration of force elements to achieve an effect by a particular equipment or physical system enabled through DLoDs. This is associated with operational capability to achieve a military effect e.g. deep strike and air defence which are driven by the need to respond to military threats.

Industrial viewpoints focused on the technical capability, including the equipments and interoperable systems. Industrial stakeholders also emphasised the business capability that is needed to meet customer requirements aligned with DLoDs e.g. the ability to make, buy and sell goods and services to a client. This is the capability a company needs in order to fulfil its business aspirations and obligations. Some functions of industry considered capability as knowledge and experience rather than equipment. Capability is consequently understood to be outcome focused and context dependent.

The UK MoD AOF [2] definition of TLCM states that TLCM translates the defence policy into an approved programme that delivers the required capabilities, through life, across all DLoDs. The stakeholder perception of TLCM varied. For some, it is the latest initiative or a fad that will last a few years. For others, it differs from life-cycle management of tangible capability to an enterprise business operating model that provides a framework for the transformation of defence needs to device and reduces long-term costs. The MoD-based stakeholders' view of TLCM is made excessively complicated and no one consistent MoD view of TLCM exists despite the AOF definition. Some view TLCM as a meeting structure or change program whereas others consider it as a methodology. TLCM is also regarded as the realisation of military capability (via force packages) against a pre-determined strategic need in accordance with the overarching doctrine or concept of operations of the UK. The TLCM planning across the DLoDs still seems very immature and equipment centric.

Similarly with MoD, industry has no cohesive view of TLCM. The majority of the employees never heard of TLCM apart from through newsletters. The perception of some lines of business are equipment based and refer to managing the equipment through its life from concept to disposal limited by the contract. Industry is also sceptical, believing that MoD may discontinue TLCM. Some stakeholders regard TLCM as a new marketing opportunity providing more services and equipment to MoD. Only a minority understand the concept of TLCM as a top-down, planned and co-ordinated mechanism to create military effect. It is also worth noting that capability is realised against an operational need, but the planning of capability is against strategic need and doctrine, and a set of pre-defined military tasks. Within both industry and MoD there are two distinct communities; those that regard TLCM as planning of capabilities (i.e. a planning process for acquisition) and those that regard it as maintenance of systems including reduced maintenance costs (i.e. cost of ownership).

\section{3) Root definitions and the Transformation Process}

The stakeholders were asked to identify the CATWOE elements relevant to the following transformation process $(\mathrm{T})$ : " a set of activities needs to be developed to transform the industry business model to support TLCM'. This involved transforming the current industry business model (input) into a new business model applicable to TLCM (output). Input $\rightarrow$ Transformation Process $\rightarrow$ Output

The results for CATWOE definition are shown below:

- Customers: military customer including $\mathrm{MoD}$ and home markets; front line command; industrial business units, engineering directors, shareholders and employees; supply chain; and taxpayers.

- Actors: military customer; all engineering managers; industrial leadership, employees and subcontractors; functions within business units e.g. technical, commercial and business development; and integrated project teams.

- Transformation process (T): as described above.

- Weltanschauung (worldview): changing business from purely equipment providers to a provider of equipment and support services; service improvements to customer and commercial benefits to the industry; long term evolutionary view rather than single transaction view; latest initiative; reputation and public perception of the support provided to front line; profit to taxpayers; and affordability that will make this meaningful. 
- Owners: Same as actors

- Environmental Constraints: shrinking defence budgets; legacy equipment programmes; manufacturing culture (hierarchical and product focused); increasing instability in the world hence change in threat nature e.g. asymmetric warfare; and a new government agenda.

The victims of this transformation process include the people that cannot adapt to change and, therefore, to the new business model. Checkland [10] states that it is a good idea that different worldviews are used to develop different root definitions. Therefore, a similar top-down approach will be used in the future to investigate TLCM holistically leading to the development root definitions derived from participants perception of TLCM and worldviews mentioned above.

\section{4) Human Activity Model}

Following the root definitions, the stakeholders $(n=16)$ listed up to seven activities they carried out in their day-to-day business that supported TLCM and represented this using SSM's human activity (conceptual) model. They indicated the extent to which the activities supported TLCM by ranking them from most important (1) to least important (7). A total of 93 activities, that is an average of almost 6 activities per person, were identified. The mean time spent on activities is $87 \%$ and the range is $75 \%$. The activities were then put into a pre-identified time scale matrix summarised below.

Table 1. Activity time scale matrix

\begin{tabular}{|l|c|c|}
\cline { 2 - 3 } \multicolumn{1}{c|}{} & Short Term Impact & Long Term Impact \\
\hline Short Duration & 17 & 36 \\
\hline Long Duration & 26 & 39 \\
\hline
\end{tabular}

To understand the individual stakeholder interpretation of long and short term, scenarios were created applicable to the above time scale matrix. For example, a scenario with a long duration and long term impact was identified to be project management processes and best practice as this involves a continual improvement over a long period. An example scenario for a short duration and long term impacts is the specification of the roles and responsibilities of the Systems Engineers in TLCM, which includes writing a document that can be used by programme boards to specify the competencies required for Systems Engineers. Once written, it can be published in Acquisition Guidance therefore having a long term impact. Another example is the design of TLCM processes as it is a short duration task but if successful it can become a doctrine.

The stakeholders built their own TLCM activity model $(n=16)$ by selecting the activities which could be done at once; then those dependent on a line below; and continued until all activities were accounted for as shown in the Figure 3.

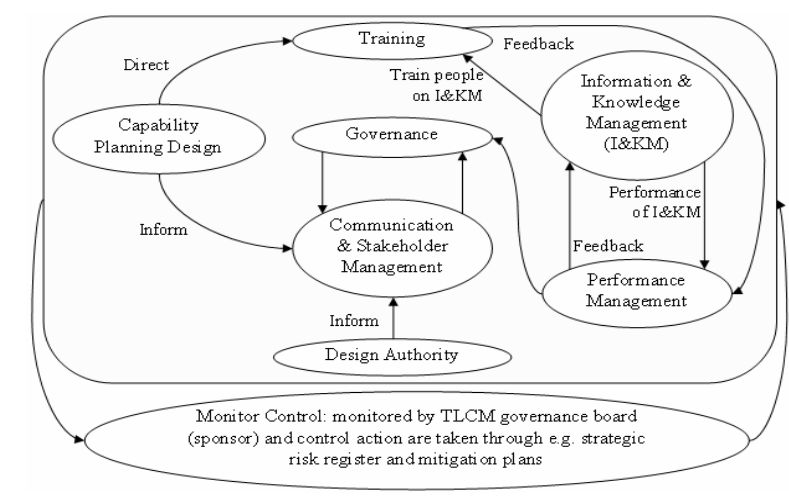

Figure 3. An example of a Human Activity Model

\section{5) Ontology Development}

The human activity models developed consider the perception of each SME. A bottom-up approach was used to generate a TLCM ontology derived from the composite of activities that SMEs produced. The activities $(n=93)$ were analysed to identify similarities and eliminate duplications to create the following refined list $(n=36)$.

Table 2. Ontology derived from Human Activity Models

\begin{tabular}{|l|l|}
\hline - Learning \& Development & - Knowledge Management \\
- Research & - Performance Management \\
- Tools \& Technology & - Advice \\
- Processes & - Road-mapping \\
- Readiness \& Sustainment & - Modeling: activity/process \\
- Service Support & - Spanning Measures \\
- Roles \& Responsibilities & - TLCM know-how \\
- Systems Engineering & - Lifecycle Management \\
- Updating the AOF & - Best Practice \\
- Stakeholder Management & - Capability Investigations \\
- People Capability & - TLCM Working Group \\
- Integration of Functions & - Strategies \\
- Project Management & - Capability Development \\
- Consultancy & - Affordability \\
- Governance \& Ownership & - Exploitation \\
- Capability Planning & - Capability requirements \\
- Design Authority & - Auditing/reviewing \\
- Sponsorship & - Assurance \\
\hline
\end{tabular}

The above activities were defined by stakeholders and some are supported by corresponding scenarios. For example, the learning and development activity includes mentoring, education, training and conferences; and the governance and ownership activity is associated with supply chain, engineering and project management functions. Figure 4 shows the TLCM activity ontology derived from the previous list.

This ontology defines a common vocabulary to help stakeholders to share a common understanding of TLCM. 


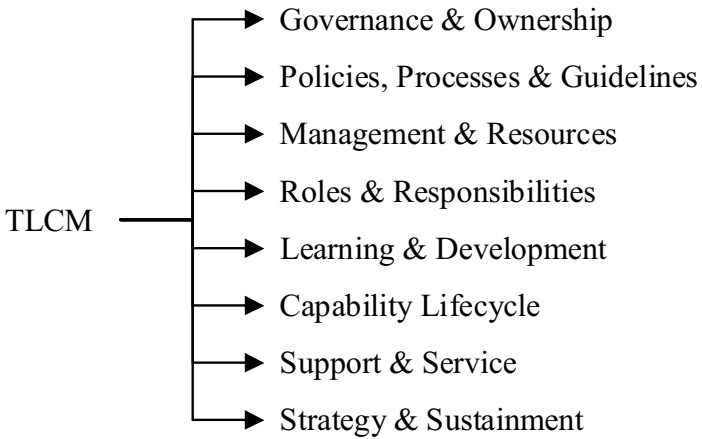

Figure 4. Level one of the TLCM Activity Ontology

\section{DISCUSSION}

This paper examined three aspects; (1) a conceptual approach to through-life business transformation by adopting SSM, (2) the derived semi-structured interview results, and (3) human activity model and ontology development to support TLCM. Capability and TLCM are also contextualised through analysis of the stakeholder viewpoints. This leads to the conclusion that there are three main communities within the TLCM enterprise; planning, implementation and education community. Those involved in planning engage in changing the behaviors of others; the implementation community deals with e.g. maintenance; and the education community can be described as messengers and evangelists.

Soft Systems Modeling is more appropriate to TLCM than 'hard' representations (e.g. IDEF0, ...), because, when put into context, it can only be delivered through 'soft' behaviours e.g. interactions between functions and stakeholders within the enterprise. This is also emphasised by Ward and Graves [13] who state that "the provision of seamless through-life customer solutions depends heavily on collaboration, co-ordination and co-operation between different parts of an enterprise, different companies within a group, other manufacturers, support contractors, service providers and all their respective supply chains".

The SSM conceptual models developed in this paper are not activity models of TLCM. These are activity models of how each stakeholder supports TLCM. The Authors believe that this can guide the future through-life business transformation. It is also important to mention that industry does not perform TLCM; only MoD can realise it. Industry supports TLCM via Through Life Management (TLM) where TLM is defined as the philosophy that brings together the behaviours, systems, processes and tools to deliver and manage projects through the acquisition lifecycle [2]. TLM is usually about platform or equipment based strategies that seek to achieve better availability and a more integrated approach to technology insertion, updates and upgrades through the life of the platform or equipment. Whereas TLCM is about pan-LoD crossplatform strategies that seek to achieve better capability at the front line and better value for money through effecting changes in one or more of the DLoDs and/or exploiting synergies across similar platform types [14].

The results from this conceptual SSM approach can be aligned with a change management programme and future business aspirations to enable communality across the TLCM enterprise. The Authors believe that a top-down approach is also necessary to investigate the processes at a higher level rather than in detail to populate the cube model or support a future TLCM model development. This top-down approach can include the analysis of the descriptions from the semistructured interview to create different root definitions.

There appears to be confusion within industry about the roles of lifecycles (e.g. CADMID), DLoDS, and capability. This is probably due to the preconceptions about lifecycles such as CADMID being applicable to all aspects of capability, whereas some aspects (e.g. doctrine) clearly do not fit this model. Considering the TLCM Cube model (Figure 2), it is noted that industry is only concerned with levels 1 and 2, whereas MoD must deal with all levels (1-5). The cube model promotes a process-based view of TLCM, whereas the SSM modeling leads to an understanding of the nature of collaborative interactions in TLCM and the fact that it is also about a change in culture.

This research has not sought statistical significance, nor has it attempted to assess the impact of SSM on TLCM modeling. Instead, the aim was to identify possible patterns in SMEs' perceptions and viewpoints that would guide future model development for TLCM and transformation. Although the SMEs interviewed were drawn from a broad representation of the TLCM enterprise, they by no means accounted for all the functions. Additional research is warranted to investigate a more comprehensive range of TLCM activities.

\section{CONCLUSIONS}

This paper presented the result from semi-structured interviews, and used a bottom-up approach, to create a TLCM ontology in support of future conceptual model development. Soft Systems Methodology was adopted as an approach to identifying the activities necessary to transform an existing aerospace and defence business model into one that would support TLCM.

The results indicate that TLCM needs to be considered holistically leading to the analysis of interdependent activities that need to be transformed. Activities can be visualised as interlocking Lego bricks comprising regular Capability activities, TLCM activities, and activities to enable the TLCM activities. It is necessary to identify and develop new activities to enable a better through-life business transformation. In addition, the conceptual models already developed can be studied further to understand the interactions and behaviours of different functions e.g. maintenance and service support; supply chain management; and project management within the TLCM enterprise. The Authors suggest the necessity of a topdown approach that can be used to develop the root definitions 
derived from the SMEs' perception of Capability and TLCM. This holistic approach can be used to create a general activity model of TLCM that may be compared to the results of the bottom-up approach already conducted.

\section{ACKNOWLEDGEMENTS}

This research has been supported by the Systems Engineering Doctorate Centre, sponsored by EPSRC and BAE Systems.

\section{REFERENCES}

[1] Defence Industrial Strategy (DIS): Defence White paper, The Stationery Office (TSO), UK Ministry of Defence, ISBN 0101669720, p.17, December 2005.

[2] UK MOD Defence Acquisition Operating Framework, Version 2.0.21, www.aof.mod.uk, Accessed March 2010.

[3] A. Harding, J. Mollett and M. Touchin, "A structured approach to planning and managing systems engineering capability evolution in a complex through-life business space", Proceedings of the 7th Annual Conference on Systems Engineering Research, pp. 3-5, April 2009

[4] R. Barton, "Managing the Trading Environment in practice TRAiDE", Integrated Enterprise Architecture Conference, London, February 2009

[5] A. J. Daw, "MOD-Industry Developments in Capability Management An ECG View", IET Forum on Capability Engineering: At Home and Abroad, London, November 2006.

[6] G. Symes and A. J. Daw, "On the Use of Information Management in the context of TLCM", Journal of Naval Engineering, Vol 45, No. 2, December 2009.

[7] A. Tetlay and P. John, "Determining the Lines of System Maturity, System Readiness and Capability Readiness in the System Development Lifecycle", 7th Annual Conference on Systems Engineering Research, April 2009

[8] E. I. Neaga, M.J.d.Henshaw and Y. Yue, "The Influence of the Concept of Capability-based Management on the Development of the Systems Engineering Discipline", 7th Annual Conference on Systems Engineering Research, April 2009.

[9] P. Checkland, Systems Thinking, Systems Practice, John Wiley and Sons, London, 1981.

[10] P. Checkland and J. Scholes, Soft Systems Methodology in Action, John Wiley and Sons, Chichester, 1990.

[11] H. Dogan and M.J.d. Henshaw, "Transition from 'soft' systems to an enterprise knowledge management architecture", Contemporary Ergonomics 2010: Proceedings of the Ergonomics Society Annual Conference, Keele University, UK, April 2010.

[12] S. Burge, "Systems Approach, Analysis and Concepts", ELP061 Course Learning Material, Engineering Doctorate programme, Loughborough University, UK, 2008.

[13] Y. Ward, and A. Graves, "Through-life management: The provision of total customer solutions in the aerospace industry". International Journal Services Technology and Management, pp. 455-477, 2007

[14] B. Taylor, "Presentation: TLCM Overview". Defence Science and Technology Laboratory (Dstl), UK, 2006. 